\title{
DETERMINAÇÃO DA INDIVIDUALIDADE EM HEGEL
}

\author{
Adriano Blattner Martinho
}

\begin{abstract}
RESUMO: A fim de sugerir diretrizes de pesquisa sobre o modo de determinação da individualidade no pensamento hegeliano, o presente artigo reacende as invectivas filosóficas da Fenomenologia do Espírito contra a Psicologia, a Frenologia e a Fisiognomonia.
\end{abstract}

Palavras-chave: Hegel; Individualidade; Psicologia; Frenologia; Fisiognomonia

\begin{abstract}
In order to suggest guidelines for research on the art of individuality determination in Hegel's thought, this paper arouses the philosophical invectives against Psychology, Phrenology and Physiognomy in the Phenomenology of Spirit.
\end{abstract}

Key-words: Hegel, Individuality; Psychology; Phrenology; Physiognomy

Buscar em Hegel a compreensão do modo de efetivação da individualidade pode parecer infrutífero, se o esforço necessário for comedido ao sabor do vendaval que propaga a má reputação do filósofo quanto a este tema. A recepção do legado hegeliano, a despeito de sua miríade de matizes, consolidou um juízo bastante difuso acerca da inépcia de Hegel para responder a essa ordem de exigências: a individualidade seria justamente o calcanhar de Aquiles de uma filosofia mais disposta a perpetrar quaisquer sacrifícios para subjugar os múltiplos aspectos da vida a um princípio unitário. Neste breve artigo se procura lançar uma suspeita sobre esse juízo. No influxo da crítica hegeliana ao conceito transcendental de sujeito, argumenta-se, com base na exegese do autor, que o reconhecimento da realidade dos universais e a postulação do espírito como princípio de individuação não implicam determinação prévia do caráter individual.

Comecemos pela seguinte passagem da Estética, na qual, em vista da influência que Fichte acabaria por exercer sobre a escola romântica, Hegel desenvolve sua

\footnotetext{
${ }^{1}$ Mestre em Filosofia pela Faculdade de Filosofia, Letras e Ciências Humanas da Universidade de São Paulo (FFLCH/USP). O presente artigo constitui uma versão abreviada da segunda parte da dissertação de mestrado do autor, intitulada "Os momentos literários da individualidade moderna na Fenomenologia do Espírito de Hegel”. Artigo submetido em 12 de dezembro de 2010.
} 
conhecida crítica do Eu abstrato em direção a uma reflexão sobre a individualidade humana:

\begin{abstract}
Fichte estabelece o Eu e, na verdade, o Eu total e constantemente abstrato e formal, como princípio absoluto de todo saber, de toda razão e conhecimento. Em segundo lugar, esse Eu é por causa disso em si mesmo completamente simples; por um lado, nele são negados toda particularidade, determinação e conteúdo - pois todas as coisas sucumbem nesta liberdade e unidade abstrata -; por outro lado, todo conteúdo que deve valer para o Eu somente é estabelecido e reconhecido pelo Eu. O que é, somente é através de mim, e o que é através de mim posso do mesmo modo aniquilar novamente. Se, porém, ficamos presos a estas formas totalmente vazias que têm sua origem no caráter absoluto do Eu abstrato, nada é considerado em si e para si e em si dotado de valor, mas somente enquanto produzido pela subjetividade do Eu. E então o Eu também pode permanecer senhor e mestre de tudo o que existe e nada haverá em nenhuma esfera da eticidade, do direito, do humano e do divino, do profano e do sagrado que não necessite ser primeiramente estabelecido pelo $\mathrm{Eu}$ e que, por isso, também não possa igualmente ser destruído pelo Eu. Por causa disso, tudo o que é em-si-e-para-si é apenas uma aparência e não é verdadeiro e efetivo devido a si mesmo e por meio de si mesmo, mas um mero aparecer por meio do $\mathrm{Eu}$ que, com violência e arbitrariedade, dispõe livremente de tudo o que é em-si-e-para-si. Atribuir valor a algo ou superá-lo depende totalmente do bel-prazer do Eu que, enquanto Eu, já é absoluto em si mesmo. Em terceiro lugar, este Eu é indivíduo vivo, atuante, e sua vida consiste em fazer sua individualidade para si e para os outros, em se manifestar e se tornar fenômeno [sich zu äußern und zur Erscheinung zu bringen]. Pois cada homem, na medida em que vive, busca se realizar e se realiza.
\end{abstract}

O excerto acima deixa clara a impropriedade de se imputar a Hegel certo comprometimento em justificar uma tirania sistemática do sujeito sobre o objeto, do Eu sobre o Outro, ou da razão sobre a vida. E ainda sugere que, na seara das ideias, a tirania medra mais perto da diluição da realidade na subjetividade do que da perseverança em ater a consciência àquilo que é "verdadeiro e efetivo devido a si mesmo e por meio de si mesmo".

A reflexão hegeliana sobre a individualidade visa a superar o dualismo entre corpo e alma que prevalecia na filosofia pelo menos desde que Descartes preceituara ser a alma "uma substância inteiramente distinta do corpo."3 Sabemos que Kant e Fichte ainda permaneceram presos a essa rígida estratificação. Mas nenhum passo adiante se teria dado caso a assertiva hegeliana de que a verdade do Eu reside no "indivíduo vivo e

\footnotetext{
${ }^{2}$ G. W. F. HEGEL, Cursos de Estética, Introdução, p. 81-82. Grifo meu.

${ }^{3}$ R. DESCARTES, Princípios da Filosofia, $\S 8$.
} 
atuante" evocasse uma reconciliação teórica do dualismo na figura de um corpo animado ou de uma alma encarnada. A mediação que Hegel assinala dar-se no indivíduo reporta, do contrário, à reconciliação prática entre particular e universal que ocorre porque "mediante o Si enquanto alma a substância é plasmada em seus momentos". 4 Em vez de deduzir o campo de experiência do indivíduo de um fundamento transcendental, Hegel se propõe a explicitar como o indivíduo mesmo plasma a substância universal que lhe serve de fundamento.

Tomando-se o indivíduo por objeto, seja como for, nem a representação de uma alma encerrada no corpo e nem a de um corpo dotado de alma exprimem o próprio indivíduo como sujeito universal. A origem de sua alma permanece incógnita, e ao dualismo resta explicar a alma como predicado de um sujeito estranho. Mas o dualismo já está suplantado na unidade que a consciência precisa estabelecer com a efetividade para entrar em ação. "Essa unidade negativa do pensar é para si mesma, ou melhor, é o ser-para-si-mesmo, o princípio da individualidade; e é, em sua realidade, consciência operante". 5 Eis que se manifesta a necessidade de considerar a atividade da alma, o seu confronto com o múltiplo, de modo mais abrangente do que a mera apercepção cognoscitiva. Para Kant, a alma era apenas um "objeto do sentido interno", 6 e sua única atividade era conhecer. A estratégia hegeliana amplia enormemente o campo de observação dos fenômenos de exteriorização da subjetividade.

A filosofia moderna, até então, consagrara seus maiores esforços à investigação do funcionamento da consciência, das leis racionais do entendimento, da estrutura interna do Eu. Mas Hegel nos adverte que por sobre essas bases não se consegue explicar satisfatoriamente o homem: "pois cada homem, na medida em que vive, busca se realizar e se realiza." Se a atividade vital dos indivíduos consiste em implementar a consciência no ser, então a ciência precisa se abrir aos processos pelos quais a potência subjetiva se transfunde para a objetividade.

\footnotetext{
${ }^{4}$ G. W. F. HEGEL, Fenomenologia do Espírito, VI, B, 1-a -“A cultura e o seu reino da efetividade”, p. 341 (366). Nas citações da Fenomenologia do Espírito, indica-se entre parênteses, após o número de página da tradução brasileira, a página correspondente no oitavo volume da edição alemã das obras completas de Hegel, discriminada na bibliografia.

5 Id., Fenomenologia do Espírito, V, A, b - "Observação da consciência-de-si em sua pureza e em referência à efetividade exterior: leis lógicas e leis psicológicas”, p. 218 (228-229).

${ }^{6}$ I. KANT, Crítica da Razão Pura, Capítulo Primeiro do Livro Segundo da Dialética Transcendental, p. 261.
} 
Na Fenomenologia do Espírito, reside um capítulo penetrante dessa crítica ao despreparo da ciência existente para conceber o homem como ser ativo. Na terceira seção da obra, Hegel enceta polêmica contra três ramos do conhecimento dedicados à investigação da individualidade humana: a Psicologia, a Frenologia e a Fisiognomonia. À procura de um modo efetivo de determinação da essência absoluta da individualidade, trata-se de expor a deficiência de representações que reduzem o indivíduo a objeto de apercepção. Levantemos alguns elementos notáveis desse esforço hegeliano.

\section{a) Psicologia}

Pertence a Christian Wolff (1679-1754) a decantada divisão da Psicologia em Psicologia Empírica e Psicologia Racional, esta dedicada a indagações metafísicas sobre a origem da alma, e aquela ao estudo da subjetividade enquanto fenômeno da experiência humana. Na crítica do paralogismo, Kant reafirma essa divisão ao destituir a Psicologia Racional de objeto real. Parece, pois, que restaria ao outro ramo a possibilidade de angariar algum conhecimento do Eu. Dentre os estudos de Psicologia Empírica se destaca o famoso tratado de Descartes acerca Das Paixões da Alma, no qual são descritos, com profusão de detalhes, os variegados estados de ânimo e as influências recíprocas entre corpo e mente.

Hegel considera que, ao adotar o procedimento de observação da individualidade, a Psicologia empreende uma primeira tentativa de condicionar as formas da consciência à experiência. O método empírico desloca o foco da disciplina, do exame das faculdades de um sujeito amorfo para a apreensão dos predicados da consciência finita. Deixando de lado o problema do dualismo, a Psicologia chega a reconhecer no indivíduo a unidade da consciência com o seu contrário.

A psicologia observadora enuncia, primeiro, suas percepções dos modos universais que se lhe apresentam na consciência ativa; encontra numerosas faculdades, inclinações e paixões. Ora, na enumeração de tal coleção não se deixa reprimir a lembrança da unidade da consciência de si; por isso a psicologia deve, ao menos, chegar até o ponto de maravilhar-se de que possam estar juntas no espírito, como num saco, tantas coisas tão contingentes e heterogêneas, especialmente porque não se mostram como coisas mortas, mas como movimentos irrequietos. Na enumeração dessas diversas faculdades, a observação está no lado universal: a unidade dessas 
múltiplas capacidades é o lado oposto a essa universalidade: a individualidade efetiva. ${ }^{7}$

Mas Hegel também adverte que a Psicologia não pode se desembaraçar da metafísica simplesmente delegando a investigação das condições de existência da alma a uma especialidade teórica que se reduziu ao diletantismo, paralisada pela incognoscibilidade da essência absoluta. Ele nos mostra como a insolvência teórica se faz sentir na ciência aplicada, na medida em que mesmo o estudo descritivo do eu fenomênico continua minado pelo conceito transcendental de sujeito. A persistência da unidade sintética originária como princípio operador do entendimento relega a observação psicológica àquele "procedimento raciocinante" 8 de atribuir inúmeros predicados ao sujeito sem jamais formular o conceito que lhe determine a essência, e que leva, no caso, a um catálogo de sedes anatômicas das múltiplas disposições anímicas.

A Psicologia só reconhece a unidade entre corpo e alma como um objeto empírico sob a mira da razão; isto é, ela representa a individualidade separada de "sua natureza inorgânica universal, ou seja, as circunstâncias, situações, hábitos, costumes, religião etc. que são 'achados' e em função dos quais a individualidade determinada tem de ser concebida". 9 Se não se leva em conta a influência dessas circunstâncias determinadas sobre a individualidade, aniquilando-se a universalidade na figura abstrata do Eu, então as disposições anímicas parecem ser apenas predicados intrínsecos que não têm nenhuma razão precisa para se manifestarem de certo modo na vida sensível, e "a necessidade psicológica se torna uma palavra tão vazia que se dá a possibilidade absoluta de que o indivíduo que teria tido aquela influência pudesse também não ter tido." 10 O universal não pode ser um elemento indiferente; há de se considerar o papel do mundo na conformação da alma. Assim, a principal objeção de Hegel à Psicologia recai sobre a pretensão de deduzir o caráter do indivíduo de uma análise da interioridade.

\footnotetext{
${ }^{7}$ G.W. F. HEGEL, Fenomenologia do Espírito, V, A, b - "Observação da consciência-de-si em sua pureza e em referência à efetividade exterior: leis lógicas e leis psicológicas,” p. 219 (230).

${ }^{8}$ Id., Fenomenologia do Espírito, Prefácio, p. 62 (56).

9 Id., Fenomenologia do Espírito, V, A, b - "Observação da consciência-de-si em sua pureza e em referência à efetividade exterior: leis lógicas e leis psicológicas,” p. 220 (231).

${ }^{10}$ Ibid., p. 221 (232).
} 
Tem menos interesse do que descrever as espécies de insetos, musgos etc., isso de apreender as diferenças efetivas, de modo a descrever um homem como tendo mais inclinação a isso, e outro, mais inclinação àquilo; que fulano tem mais inteligência que sicrano. De fato, espécies vegetais e animais dão à observação o direito de tomá-las assim, de modo singular e carente-deconceito, pois pertencem essencialmente ao elemento da singularização contingente. Ao contrário, tomar a individualidade consciente de uma maneira carente-de-espírito, como fenômeno singular essente, tem a contradizê-lo o fato de que sua essência é o universal do espírito. ${ }^{11}$

Na polêmica contra a Psicologia, ainda, ao discutir sobre como a universalidade do espírito deveria ser conceitualmente incorporada à determinação da individualidade, Hegel parece defender-se de vindouros detratores, com a advertência de que representar o indivíduo como particularização de um estado do mundo, em contrapartida, também não resolve o problema. "Circunstâncias, situações, costumes etc., que uma vez são indicados como dados, e outra vez são indicados nesta individualidade determinada, somente exprimem a essência indeterminada da individualidade - da qual não se trata aqui." ${ }^{\prime 12}$ De fato, não há grande diferença entre explicar o indivíduo como manifestação de predicados intrínsecos ou como confirmação de predicados extrínsecos, pois, no segundo caso, o pensamento ainda opera segundo a mesma dicotomia. Hegel não aceita conceber a individualidade como fruto da configuração do mundo; isto é, ele também não aceita, em remedeio ao subjetivismo psicológico, que o caráter do indivíduo seja deduzido de uma análise do estado de coisas ou identificado a características gerais da época. "Fosse o exterior constituído, em si e para si, tal como se manifesta na individualidade, essa seria bem compreensível a partir dele. Teríamos então uma dupla galeria de quadros, em que uma seria reflexo da outra; uma, a galeria da determinidade completa e da delimitação das circunstâncias exteriores; outra, a mesma galeria, mas traduzida nessa modalidade segundo a qual as circunstâncias estão dentro da essência consciente." ${ }^{13}$ O caráter seria decidido por uma conjunção de fatores objetivos, de modo que cada momento do desenvolvimento da individualidade corresponderia a um arranjo estabelecido no plano das constelações, das instituições, da religião, da arte, da ciência, da história, enfim - da substância universal. Todavia, segundo Hegel, não é esse o caso. O indivíduo não está para o mundo como

\footnotetext{
${ }^{11}$ Ibid., p. 221 (232).

12 Ibid., p. 220 (231).

${ }^{13}$ Ibid., p. 221 (232).
} 
uma árvore para a paisagem; ele não está para o espírito da época como que amarrado perante um espelho. E por que não?

Eis o argumento fundamental: nada vem a ser para a individualidade senão por meio dela mesma. "Essa individualidade consiste justamente nisto: em ser o universal e portanto em confluir de uma maneira tranqüila imediata com esse universal que está presente como costumes, hábitos etc.; e, ao mesmo tempo, em comportar-se como oposta a eles, e portanto em subvertê-los; como também comportar-se, em sua singularidade, com total indiferença a seu respeito, não os deixando agir sobre ela, nem sendo ativa contra eles." ${ }^{\prime 14}$ Em suma, a concordância originária entre singular e universal pode ser negada em ato. O ser singular é sempre universal em si, mas para si ele pode ser apenas singular, e neste caso será a negação o determinante da universalidade que o ser singular se dá. Assim, do fato de o indivíduo pertencer à substância não se segue que sua conduta esteja predeterminada unilateralmente. Em primeiro lugar, porque as circunstâncias exteriores só ganham influência sobre o indivíduo conforme o modo determinado como ele próprio responde a elas. Em segundo, porque sua resposta admite ao menos duas possibilidades: ou aceitar ou recusar, em diversos graus e de várias maneiras, as influências que recebe do mundo. "Só da própria individualidade depende, pois, o que deve ter influência sobre ela, e qual influência isso deva ter - o que vem a dar exatamente no mesmo. Portanto, dizer que tal individualidade, mediante essa influência, se tornou esta individualidade determinada não significa outra coisa senão que ela já era isso antes." ${ }^{15}$ Engana-se quem considera o indivíduo uma repercussão do estado do mundo sob alegação de que é de sua essência ser universal. Que a individualidade necessariamente dê vazão ao fluxo do espírito ainda não revela nada de determinado sobre ela. E esta inflexão mobiliza muito mais do que a ênfase na margem de liberdade individual envolvida na definição do destino. Simultaneamente, para Hegel, trata-se de introduzir o negativo no conceito de manifestação fenomênica. O fenômeno não deve ser concebido como repetição desvelada de um mesmo conteúdo originário. Mais do que resguardar a oposição ao universal como possibilidade formal de conduta, Hegel está a defender que a manifestação pela negação constitui a verdadeira via de determinação da essência da individualidade. (Lembremo-nos de Fichte, para quem a negação do eu puro pelo eu empírico era tão-somente uma perda de

\footnotetext{
${ }^{14}$ Ibid., p. 220 (231).

15 Ibid., p. 220 (231).
} 
si que nada afirmava além de uma dívida impagável da existência para com a essência.) A peculiaridade do indivíduo decorre dos atos com que ele se diferencia, e não dos atributos que o igualam ao todo. Não há que se falar em determinação enquanto o indivíduo apenas espelha as influências a que se submete. Dizer que "o indivíduo não seria o que é se essas circunstâncias, maneiras de pensar, costumes, estado-do-mundo em geral não tivessem sido"16 é apenas uma obviedade, válida para todos os casos ocorridos sob as mesmas condições. A determinação da verdadeira essência universal do indivíduo consiste não em evidenciar a universalidade do ser singular, mas em distinguir a singularidade do ser universal.

Tranquillo quilibet gubernator est. ${ }^{*}$ Se o indivíduo apenas confluísse com o leito da vida, sem nenhuma revolta - se ele jamais se chocasse contra imposições superiores, se jamais divergisse dos preceitos vigentes, se jamais ofendesse esperanças alheias - então mesmo assim essa aparente passividade perante o estado do mundo ainda seria, na verdade, ativa: pois neste caso ele próprio "teria feito entrar em si o mundo tal como é, comportando-se a seu respeito como consciência formal."17 Mas a dinâmica da experiência individual não se resume a singrar serenamente a substância universal, como um timoneiro qualquer. A influência da efetividade sobre o indivíduo também "recebe, através desse indivíduo, o sentido inteiramente oposto: o indivíduo ou deixa correr imperturbado o fluxo da efetividade que o influencia, ou então o interrompe e o inverte." ${ }^{18}$ E o conceito de individualidade não deveria ignorar sobretudo a segunda alternativa, porque só pela conduta negativa a identidade imediata da essência se quebra e a consciência formal vem a adquirir conteúdo próprio - a singularidade surge. Assim, o modo necessário de manifestação da efetividade na singularidade não está determinado em potência. Tomar o espírito por senhor absoluto do destino leva à mera representação de uma existência formal, como se o mundo transferisse para a individualidade o caráter que ele engendrou primeiro. "Como, pois, a efetividade é susceptível de uma dupla significação em virtude dessa liberdade, então o mundo do indivíduo tem de ser concebido a partir do indivíduo mesmo.”19

\footnotetext{
${ }^{16}$ Ibid., p. 220 (231).

${ }^{17}$ Ibid., p. 220 (231).

${ }^{18}$ Ibid., p. 220 (231).

* Na calmaria, qualquer um é timoneiro. - Sêneca, Epistulae Morales 85.34

${ }^{19}$ Ibid., p. 220 (231).
} 
Se a Psicologia se consagra à análise da alma, a Frenologia e a Fisiognomonia, por sua vez, procedem à observação do objeto oposto, tentando descobrir o caráter do homem pela investigação de traços corporais: feições e proporções de um indivíduo dariam a conhecer sua exata propensão para determinada conduta. A veemência com que Hegel repudia esses estudos salta aos olhos do leitor versado na habitual sobriedade estilística do filósofo. Pois se, por um lado, a Psicologia falha em determinar a influência da objetividade, nenhum ganho de objetividade se obtém, por outro, com a associação do caráter a predicados objetivos. A Frenologia e a Fisiognomonia pretendem corrigir o subjetivismo da Psicologia com a hipótese de que as disposições anímicas provenham de respectivos lineamentos físicos. Mas supor que a essência espiritual do indivíduo possa ser identificada pela figura do corpo é um erro ainda maior, porque cassa a autonomia moral do homem na própria singularidade.

Socorramo-nos de Ronaldo Mourão para enriquecer a exposição deste tema. $\mathrm{O}$ erudito astrônomo situa a Frenologia e a Fisiognomonia na história da ciência, em avaliação bastante convergente com a precursora crítica hegeliana:

A frenologia (do grego: phrén, mente; e logos, estudo) é a teoria do neurologista alemão Franz Joseph Gall (1758-1828) relativa à localização das funções cerebrais, primeira das tentativas científicas de medir o formato do crânio e tentar estabelecer uma relação com o caráter e a personalidade do indivíduo. Além de ser considerado o fundador e pai da frenologia, Gall foi um dos primeiros a sugerir cientificamente o cérebro como sede de todas as atividades mentais. Em Paris, na obra Sur les fonctions du cerveau (1825), escreveu sobre "a anatomia e fisiologia do sistema nervoso em geral e do cérebro em particular, com as observações sobre a possibilidade de reconhecer várias disposições intelectuais e morais do homem e dos animais pela configuração de seu crânio." Muito popular no século XIX, a frenologia está desacreditada e classificada como uma pseudo-ciência. No entanto, recebeu crédito como uma proto-ciência por ter contribuído para a ciência médica com as ideias de que o cérebro é o órgão da mente com áreas específicas relacionadas a determinadas funções. (...) (...) Enquanto o anatomista e fisiologista alemão Gall acreditava na frenologia, o teólogo, filósofo e poeta suíço Johann Kaspar Lavater (1741-1801) concebeu a fisiognomonia. (...) A fisiognomonia (do grego physis, natureza, e gnómon, que conhece) pretendia associar a aparência física - em especial o rosto humano - com um determinado comportamento e, embora atualmente não possua autoridade científica, sendo considerada uma pseudo-ciência, conheceu o seu esplendor no século XIX. A fisiognomonia tem suas raízes num fato psicológico: temos uma tendência a atribuir, de modo irrefletido, uma personalidade, um caráter ou qualidades morais a um indivíduo a partir da observação de seu aspecto físico (pessoas gordas, redondas, por exemplo, evocam doçura moral etc.). A fisiognomonia tentou fundamentar-se 
cientificamente com base nessa observação e na experiência empírica de julgar as pessoas pela sua fisionomia, estabelecendo de início algumas regras e, a partir daí, tentando enunciar leis. Ao procurar objetivamente as causas de um fato (tentando constituir uma ciência) para não ficar limitada a um julgamento subjetivo (psicologia intuitiva), a fisiognomonia coordenou numerosas proposições de um ponto de vista pseudo-científico, o que impossibilitou a elaboração daquelas leis. A principal meta da fisiognomonia era, através das medidas de diferentes ângulos (por exemplo, a saliência do queixo), de formas (uma cabeça quadrada ou mais oval), das imperfeições etc., deduzir a personalidade de um indivíduo. As medidas permitiriam a matematização dos dados - o que, por sua vez, permitiria a pretensão de uma certa objetividade na nova "ciência". Mas essa teoria se baseava em critérios totalmente subjetivos; assim, por exemplo, um ângulo de mais de $45^{\circ}$ entre o eixo da mandíbula e o eixo do nariz - ou seja, uma relação quantitativa determinaria um comportamento agressivo. Neste ponto mostrou seu interesse em constituir-se em ciência, segundo as normas adotadas no século XIX para definir uma disciplina como ciência: a partir da observação de um fato ou fenômeno que poderia ser matematizado e, em seguida, por indução de leis universais, procedendo de maneira análoga à astronomia, numa imitação grosseria para obter o sucesso de Isaac Newton. ${ }^{20}$

Sabemos que a plataforma filosófica de Hegel acusa a mecânica clássica de inépcia para servir de modelo ao conhecimento científico. Eis aí o momento em que essa inépcia se manifesta com máxima severidade. A razão se propõe a conceber o homem, mas continua presa aos procedimentos de investigação da natureza. Segundo Théophile Thoré (1807-1869), autor de um dicionário de Frenologia e Fisiognomonia, as pesquisas empíricas da antropologia moderna acorriam à necessidade teórica de "absorver a dualidade na unidade." ${ }^{21}$ Para Hegel, entretanto, tudo o que elas conseguiram foi executar a pura negação da verdadeira síntese de extremos. Hegel mostra como as tentativas de superar o dualismo no interior da velha ciência resultam em empulhações grotescas.

Ao explicar por que a cognição do organismo humano não pode fornecer conhecimento do modo necessário de manifestação do caráter, Hegel paulatinamente apresenta elementos da filosofia da ação em cujo âmbito a individualidade deve ser compreendida. Assim, se a Frenologia e a Fisiognomonia acham que a figura de um homem já basta para "exprimir o que ele 'visa' por seus atos, ou o que se acredita ser ele capaz de fazer", 22 a filosofia deve, em contrapartida, "afirmar só o ato como o ser

\footnotetext{
${ }^{20}$ R. MOURÃO, $O$ animal filosófico, p. 80-83.

${ }^{21}$ T. THORÉ, De la phrénologie dans ses rapport avec l'art apud R. MOURÃO, O animal filosófico, p. 82.

${ }^{22}$ Id., Fenomenologia do Espírito, V, A, c - "Observação da consciência-de-si com sua efetividade imediata: Fisiognomonia e Frenologia”, p. 231 (243).
} 
autêntico do homem; e não sua figura". ${ }^{23}$ Pois só o ato torna efetivamente perceptíveis os movimentos de alma que antes dele se escondiam dentro do corpo. Embora o ato, tal qual o corpo, ainda seja objeto de apercepção - e, portanto, algo cuja representação isolada não suporta integralmente a essência do caráter - ocorre que nele a essência interior se dá a conhecer justamente porque ela saiu da interioridade.

$\mathrm{O}$ ato é algo simplesmente determinado, um universal, algo a ser apreendido em sua abstração: é homicídio, furto ou benefício, ato heróico etc. Pode-se dizer do ato que ele é. (...) O ato é isto, e o homem individual é o que o ato é. Na simplicidade desse ser o homem é para os outros homens uma essência universal essente, e deixa de ser algo apenas "visado". 24

Hegel segue o ensinamento aristotélico de que possuímos fins, mas só deliberamos sobre meios. A consecução do ato exige que a consciência se ajuste à efetividade, sem o que nenhuma intenção chega a ser implementada. Não é possível fazer o que não se quer fazer. $\mathrm{O}$ ato acontece quando a intenção teórica se encontra com o objeto da vontade prática. Por conseguinte, a redução da potência ao ato elimina a névoa de indeterminação que impedia a essência da individualidade de ser apreendida no interior da alma ou deduzida de características externas. É a consecução do ato que torna necessária a relação possível entre o interior e o exterior. A potência encerra possibilidades infinitas, mas o ato determina quais dessas possibilidades são realmente essenciais. A cada ato ocorre algo decisivo, pois

(...) o ato suprassume [hebt auf] a inexprimibilidade do "visar", igualmente no que se refere à individualidade consciente-de-si, que no "visar" é uma individualidade infinitamente determinada e determinável. No ato consumado, essa falsa infinitude é aniquilada. ${ }^{25}$

Disso decorrem amplas e profundas conseqüências. $\mathrm{O}$ ato põe a intenção em prática, isto é, ele ultrapassa o momento de ação formal da consciência, e, portanto, jamais poderia ser o interior como interior na exterioridade. $\mathrm{O}$ indivíduo precisa suportar a negação da subjetividade se a quiser realmente implementar. E pode até

\footnotetext{
${ }^{23}$ Ibid., p. 231 (243).

24 Ibid., p. 231 (243).

${ }^{25}$ Ibid., p. 231 (243).
} 
mesmo acontecer que o ato consumado entre novamente em conflito com a intenção; que, após o ato, quando a identidade entre meios e fins se desvanece, o indivíduo, confrontado com um mau resultado, venha a se recompor interiormente de modo a negar sua obra. "A obra é a realidade que a consciência se dá." ${ }^{26}$ Mas mesmo que o homem se recuse a reconhecer-se na própria obra, "é somente a obra que se deve considerar como sua efetividade verdadeira, ainda que o homem esteja iludido a seu respeito, e ao retornar a si mesmo de sua operação acredite que nesse interior ele é um outro do que [era] no ato." 27 A oposição da consciência formal ao próprio conteúdo não rompe o vínculo determinante do sujeito com o objeto. É preciso aceitar a verdade que destrói uma certeza como a verdade própria dessa certeza. Aquilo que se exterioriza é a manifestação da integralidade da verdade.

A incipiente questão de saber em que exata medida um indivíduo deve responder por ato que desencadeie resultado inesperado engrossa o rol de preparativos fenomenológicos para a ulterior Filosofia do Direito: quando as conseqüências contrariam ou extrapolam a intenção, cabe a este perpetrar uma separação que não pertence à essência do ato, imputando ao indivíduo somente o resultado a que ele visava. Assim, sob certas condições, o indivíduo recebe o direito de se eximir da obra. O direito de restituir a perspectiva subjetiva contra a realidade opõe a responsabilidade moderna ao conceito de culpa do mundo antigo, no qual, a exemplo de Édipo, o indivíduo era culpado pelo ato independentemente de sua intenção.

Porém, no que diz respeito à determinação do caráter, não há que se levar em conta o peso morto da potência abstrata. Hegel considera impostura a insistência em viver sob a égide da falsa infinitude. A individualidade estará enganando a si mesma se teimar que a sua essência se perdeu no ato consumado. "A objetividade não altera o ato mesmo; somente mostra $o$ que ele é, quer dizer, se é ou não é nada." ${ }^{28}$ Em suma, não existe conteúdo que subsista à sua forma de manifestação. $\mathrm{O}$ exterior exprime a essência sem deixar qualquer resíduo de pureza, pois "o que constitui o caráter do ato é isto: ser ou um Ser efetivo que se conserva; ou apenas uma obra 'visada', que some na sua

\footnotetext{
${ }^{26}$ Id., Fenomenologia do Espírito, V, C, a - "O reino animal do espírito e a impostura - ou a Coisa mesma", p. 283 (300).

27 Id., Fenomenologia do Espírito, V, A, c - "Observação da consciência-de-si com sua efetividade imediata: Fisiognomonia e Frenologia”, p. 231 (243).

${ }^{28}$ Ibid., p. 231 (243).
} 
nulidade." ${ }^{29}$ A individualidade não tem nenhum fundamento para exigir o reconhecimento de intenções e capacidades não realizadas. A explicitação da potência é condição necessária para o reconhecimento da interioridade.

\section{ช) Órgãos de manifestação e processo de exteriorização}

O indivíduo começa a se exteriorizar pelos órgãos do corpo. "Só depois ele se exprimirá mais amplamente, saindo para o exterior em sua efetividade no mundo." 30 Nos órgãos reside o agir do espírito. "A boca que fala, a mão que trabalha - e também as pernas, se quiserem - são órgãos que efetivam e implementam, que têm neles o agir como agir ou o interior como tal." "31 A presença do agir no órgão "constitui ao mesmo tempo uma exterioridade desse agir, e, sem dúvida, uma exterioridade diversa da que é o ato, já que essa nova exterioridade fica para o indivíduo e no indivíduo."32 O órgão reúne em si o interior e o exterior e "deve ser tomado como meio-termo dos dois",33 porque sua exterioridade ainda não ganhou independência. Já o ato, por sua vez, assinala ruptura entre a atividade dos órgãos e a obra consumada: "a exterioridade que o exterior ganha mediante os órgãos é o ato, como uma efetividade separada do indivíduo." ${ }^{34}$ Isso significa que a obra consumada passa a existir como objeto autônomo - como um ser-para-outro cuja essência é determinada pelo indivíduo, mas que se subtrai do ser-para-si dele.

Dentre todos os órgãos do corpo, a mão e a boca se destacam pela acuidade de intervenção, pois "o movimento que o indivíduo tem no fígado, no coração etc não pode ser considerado como movimento seu, de todo em si refletido (...)". ${ }^{35}$ Fígado e coração são órgãos que mal conseguem exteriorizar o espírito para além de si próprios e por meio de si próprios - eles se prestam mais à interiorização do que à exteriorização, mais ao sofrimento passivo do que à atitude resolutiva - este propaga os batimentos surdos do amor, aquele dissemina os humores turvos da cólera. Assim, no que diz respeito ao

\footnotetext{
${ }^{29}$ Ibid., p. 231 (243).

${ }^{30}$ Ibid., p. 227 (238).

31 Ibid., p. 224 (235).

32 Ibid., p. 226 (237).

${ }^{33}$ Ibid., p. 226 (237).

34 Ibid., p. 224 (235).

35 Ibid., p. 233 (246).
} 
modo de implementar a consciência, de obter a realização de um fim, "o indivíduo terá sua manifestação e exterioridade primeiro na boca, na mão, na voz, na escrita à mão". ${ }^{36}$ Sem descer a pormenores quanto aos demais órgãos, cumpre apenas indicar que neste capítulo, ainda a propósito da Frenologia, Hegel discorre amplamente sobre a relação do espírito com o sistema nervoso, afastando inclusive o equívoco de se identificar a consciência com o cérebro, e comenta, por fim, sobre o sentido humano da coincidência entre os aparelhos urinário e sexual, onde as funções mais baixas do indivíduo se unem às mais elevadas.

A mão e a boca, os órgãos do trabalho e da linguagem, são os meios de exteriorização que exprimem o conteúdo da interioridade com maior transparência. Porém, por mais hábeis que os meios sejam para configurar a obra, o indivíduo não pode evitar o momento em que ela finalmente escapa ao seu domínio. "Linguagem e trabalho são exteriorizações [Äusserungen] nas quais o indivíduo não se conserva nem possui mais em si mesmo; senão que nessas exteriorizações faz o interior sair totalmente de si, e o abandona a Outro." ${ }^{, 37}$ A identidade da obra consumada sofre determinações alheias. Eis aí a razão do desespero da consciência - o desespero de tomar a própria essência por objeto e já não reconhecê-la mais.

A experiência da consciência é uma concatenação de atos. Assim, a essência absoluta da individualidade se implementa ao longo de sucessivos confrontos da consciência com a objetividade. "Sobre o absoluto, deve-se dizer que é essencialmente um resultado; que só no fim é o que é na verdade." ${ }^{38} \mathrm{O}$ veredicto hegeliano de que o absoluto não se separa de sua atualização deve ser compreendido não no sentido de que o desenvolvimento se limita a corroborar um conteúdo dado em potência, mas no de que a potência mesma só adquire conteúdo por meio do processo de exteriorização. $O$ resultado desse processo como um todo é a completa aniquilação da falsa infinitude para o pensamento. Mas para compreender que o ser-para-si da potência cria a essência e que o ser-para-si da essência exprime o inteiro teor da potência, a individualidade precisa fazer experiência de que tem sua verdade na exterioridade de si.

\footnotetext{
${ }^{36}$ Ibid., p. 227 (238).

${ }^{37}$ Ibid., p. 224 (235).

${ }^{38}$ Id., Fenomenologia do Espírito, Prefácio, p. 36 (24).
} 


\section{Bibliografia}

DESCARTES, René. Princípios da Filosofia. Lisboa: Edições 70, 1997

HEGEL, Georg Wilhelm Friedrich. Werke. Auf der Grundlage der Werke von 18321845 neu edierte Ausgabe. Frankfurt am Main: Suhrkamp, 1986

Cursos de Estética I. Tradução de Marco Aurélio Werle. São Paulo: Ed. USP, 2001

Fenomenologia do Espírito. Tradução de Paulo Meneses. Petrópolis: Ed. Vozes, 2005

KANT, Immanuel. Crítica da Razão Pura. Tradução de Valério Rhoden. São Paulo: Ed. Nova Cultural, 1999

MOURÃO, Ronaldo Rogério de Freitas. “O animal filosófico”, In Entre Clássicos, São Paulo, v. 6, p. 74-83, 2006. 